\title{
Metal Oxide Particle Emissions from Diesel and Petrol Engines
}

Andreas Mayer

TTM

Jan Czerwinski

Univ. of Applied Sciences Biel-Bienne

Markus Kasper

Matter Aerosol AG

Andrea Ulrich

EMPA

John J. Mooney

John J. Mooney LLC

\begin{abstract}
All internal combustion piston engines emit solid nanoparticles. Some are soot particles resulting from incomplete combustion of fuels, or lube oil. Some particles are metal compounds, most probably metal oxides. A major source of metal compound particles is engine abrasion. The lube oil transports these abraded particles into the combustion zone. There they are partially vaporized and ultrafine oxide particles formed through nucleation [1]. Other sources are the metallic additives to the lube oil, metallic additives in the fuel, and debris from the catalytic coatings in the exhaust-gas emission control devices. The formation process results in extremely fine particles, typically smaller than $50 \mathrm{~nm}$. Thus they intrude through the alveolar membranes directly into the human organism. The consequent health risk necessitates a careful investigation of these emissions and effective curtailment.
\end{abstract}

Substantial information is available on diesel engine particulate emissions $[\underline{2}, \underline{3}, \underline{4}]$ but less for SI engines. Beside an example of metal oxide particles from a diesel engine, the present paper shows preliminary results of nanoparticles emissions of SI engines.
Four SI engines were investigated: two older and two newer engines, comprising two car engines and two motorbikes. The tests were done on standard transient driving cycles, and steady-state at constant $50 \mathrm{~km} / \mathrm{h}$ and idling. Prior investigations observed, especially during idling, high concentrations of metal oxide particles [2] . All tests were done with particle samples collected from the CVS tunnel, during a long operating period, to have sufficient material for analyzing the composition. At the steady-state points, the particle size spectra were measured.

The results show that the older SI engines emit high concentrations of soot particles and metal oxide (= ash) particles. The size distribution is decisively bimodal for both soot and ash particles.

The newer engines' emission results are less uniform and the concentrations lower, as expected. Altogether, the concentrations of these metal oxide particles are so high, that more detailed investigations are recommended. 


\section{INTRODUCTION}

Particles in the inhaled aerosols are toxic when the following conditions exist:

1. If insoluble, above all in the "surfactant" (surface-active agent) covering respiratory tissue [6].

2. If smaller than $400 \mathrm{~nm}$. The risk increases with decreasing size [ $[$ ].

3. If the composition damages the organism [2].

4. If high concentrations prevail during prolonged periods.

For most metal oxide particles, emitted by combustion engines, the above four conditions are valid. All metal oxides are toxic. The cytotoxicity of zinc and copper [7] is particularly high [2].

Medical research and engine development have intensively investigated the particle emissions from diesel engines, during the past 3 decades, and clarified many aspects [8]. The medical research showed massive effects on mortality and morbidity. Consequently, the emissions are classified as carcinogenic and more stringent air quality criteria imposed. The progressively lowered emission criteria motivated the engine manufacturers to drastically curtail formation of particles in the combustion. Subsequent exhaust-gas emission control, using Diesel particle filters, almost completely prevent particle emissions. This is verified with particle count measurement [10]. Particle counts were proven diminished by three orders of magnitude, below the mass detection threshold.

The emission directives are not yet substance specific. Both the total mass and particle count are defined independent of particle composition. However, all substances are not equally toxic. The legislation should reflect that fact to protect public health. Fortunately [2] modern particle filters for diesel engines can intercept solid particles, in the respiratory size range, both soot as also metal oxide particles, with efficiency exceeding $99 \%$.

The situation is different for SI engines. SI engines need not comply with a particle limit value. It was assumed that, during the homogenous combustion in SI engines, only very little soot is formed. Measurement of soot mass apparently confirmed the assumption. Many SI engines nevertheless emit soot that is sometimes visible. Furthermore all engines do emit metal particles. This is true for diesel, gasoline, gas and hydrogen fueled engines. Abrasion in SI engines is comparable to diesel engines. Metal oxides also originate from lube oil, fuel and catalytically coated exhaust-gas emission control devices. SI engines usually run at higher RPM and are less durable than diesel engines. Hence, SI engines probably emit more abraded particles. Do SI engines emit as many metal oxide particles as diesel engines? Are these very fine metal oxides more cytotoxic than soot particles? If so, metal oxide particles are a health hazard and must be filtered out. There are very few published studies on the questions posed. The investigations reported here are a step towards conclusive determination of SI engine metal oxide emissions and toxicity.

\section{SIZE DEPENDENT CHEMICAL ANALYSIS FOR DIESEL NANOPARTICLES}

A Liebherr 924 HD-engine was investigated in the ISO 8178/4 C1 8-points test. The procedures and the test equipment are described in [2] and [15].

During the online investigation for particle size distribution, one part of the exhaust gas passed a partial flow diluter and the ELPI. Particulate matter was collected, during $200 \mathrm{~min}$. of two complete ISO 8178 test cycles, on the 12 polycarbonate collector foils of the ELPI plus the quartz backup filter for the finest fraction. Subsequently these deposits were ICP-MSanalyzed. The results are summarized in Table 1 and represent data without DPF. Abraded metals $\mathrm{Fe}$ and $\mathrm{Ni}$ and lubrication oil metals $\mathrm{Zn}$ and $\mathrm{Ca}$ were selected for this analysis.

Without DPF, the engine Fe emission (corrected for blanks) reached $1.21 \mu \mathrm{g}$ determined as sum of the 13 ELPI stages which corresponds to $0.038 \mathrm{mg} / \mathrm{kWh}$. The $\mathrm{Zn}$ emission was even higher with $1.87 \mu \mathrm{g}$ and the $\mathrm{Ca}$ emission was much higher. All analyzed metals together cause an emission of 1.5 $\mathrm{mg} / \mathrm{kWh}$. This is quite high and supports the message of this paper to scrutinize metal emissions of engines and find technical solutions to eliminate them.

\section{TESTED SI VEHICLES}

Two vehicle pairs, a car pair and a 2-wheeler pair, were selected for the reported investigation, see Table 2 . The two older vehicles were first deployed 20 years ago, are in very good condition and in daily use. These have clocked 162,000 and $10,000 \mathrm{~km}$ respectively, which is not excessive. Both the new vehicles were first deployed two years ago and not driven much yet.

The vehicles were tested without oil change. The analysis of the old lube oil is compared to the fresh oil below.

\section{FUELS AND LUBRICANTS}

All vehicles were fuelled with the same unleaded gasoline RON 95. This gasoline complies with the European standard EN 228 and contains no metals additives (lead $<5 \mathrm{ppm}$ ). The lube oils and their compositions are described in Table 3. 
Table 1. Size dependent analysis of typical wear and lubrication oil metals in the exhaust gas of the Liebherr 924 diesel engine without DPF. Sampling during 200 min of the ISO 8178/4-C1 cycle.

\begin{tabular}{|c||c|c|c|c|}
\hline $\begin{array}{c}\text { Size class } \\
\mathrm{D} 50 \%\end{array}$ & $\mathrm{Fe}$ & $\mathrm{Ni}$ & $\mathrm{Zn}$ & $\mathrm{Ca}$ \\
\hline$[\mu \mathrm{m}]$ & {$[\mu \mathrm{g} /$ stage $]$} & {$[\mu \mathrm{g} /$ stage $]$} & {$[\mu \mathrm{g} /$ stage $]$} & {$[\mu \mathrm{g} /$ stage $]$} \\
\hline \hline 0.03 & 1.4 & 0.0119 & 2.04 & 7.3 \\
\hline 0.03 & 0.14 & 0.014 & 0.36 & 8.7 \\
\hline 0.06 & 0.08 & 0.012 & 0.57 & 8.6 \\
\hline 0.11 & $0-08$ & 0.010 & 0.22 & 2.9 \\
\hline 0.17 & 0.03 & 0.009 & 0.17 & 2.4 \\
\hline 0.27 & 0.11 & 0.028 & 0.22 & 3.6 \\
\hline 0.41 & 0.26 & 0.042 & 0.25 & 4.5 \\
\hline 0.66 & 0.09 & 0.011 & 0.19 & 2.1 \\
\hline 1.02 & 0.08 & 0.011 & 0.17 & 3.0 \\
\hline 1.65 & 0.12 & 0.011 & 0.39 & 9.5 \\
\hline 2.52 & 1.06 & 0.150 & 0.14 & 4.4 \\
\hline 4.08 & 0.15 & 0.018 & 0.41 & 11.5 \\
\hline 6.56 & 0.22 & 0.014 & 0.22 & 5.6 \\
\hline \hline Sum with blanks $[\mu \mathrm{g}]$ & 3.82 & 0.349 & 5.37 & 73.1 \\
\hline \hline Corrected for blanks $[\mu \mathrm{g}]$ & 1.21 & 0.15 & 1.87 & 45.3 \\
\hline \hline detection limit $[\mu \mathrm{g}]$ & 0.006 & 0.0002 & 0.0006 & 0.019 \\
\hline
\end{tabular}

Table 2. Test vehicles with SI engines

\begin{tabular}{|c|c|c|c|c|}
\hline Vehicle Type & Car old & Motorbike old & Car new & Scooter new \\
\hline Manufacturer & Renault R18 & Honda 450 CBR & Nissan Qashqai & Piaggio \\
\hline $\begin{array}{l}\text { Engine Volume }[\mathrm{cc}] \\
\text { Engine RPM [1/min] } \\
\text { Rated power [kW] } \\
\text { Exhaust-gas standard } \\
\text { Exhaust-gas after-treatment } \\
\text { Fuel lead free } \\
\text { Fuel consumption }[\mathrm{L} / 100 \mathrm{~km}] \\
\text { Year first deployed } \\
\text { Prior driven distance }[\mathrm{km}] \\
\text { Fuel preparation }\end{array}$ & $\begin{array}{c}2165 \\
4 \text { Cyl. } 4 \text { Stroke } \\
5000 \\
79 \\
\text { AGV } 82 \\
\text { 3W-Catalyst } \\
95 \text { RON } \\
? \\
1985 \\
162,121 \\
\text { Multipoint Port Injector }\end{array}$ & $\begin{array}{c}447 \\
2 \text { Cyl. } 4 \text { Stroke } \\
8800 \\
24.7 \\
\text { FAV } 3 \\
- \\
95 \text { RON } \\
? \\
1988 \\
\text { approx. 10,000 } \\
\text { Carburetor }\end{array}$ & $\begin{array}{c}1997 \\
4 \text { Cyl. } 4 \text { Stroke } \\
6000 \\
104 \\
\text { Euro } 4 \\
\text { 3W-Catalyst } \\
95 \text { RON } \\
8.85 \\
2008 \\
25,000 \\
\text { Multipoint Port Injector }\end{array}$ & $\begin{array}{c}124 \\
1 \mathrm{Cyl} .4 \text { Stroke } \\
8500 \\
11 \\
\text { Euro 3-C1 } \\
\text { 3W-Catalyst } \\
95 \mathrm{RON} \\
3 . .24 \\
2008 \\
1,000 \\
\text { Port Injector }\end{array}$ \\
\hline
\end{tabular}

\section{TEST CYCLES}

Table 4 lists the tested conditions. Supplementary to the official driving cycles, as prescribed for the pertinent vehicle certification, steady-state points were tested. These were at a medium load point of $50 \mathrm{~km} / \mathrm{h}$ and at idling. The load point $50 \mathrm{~km} / \mathrm{h}$ was selected to determine the particle size distribution, i.e. the particle mass was not measured at this point. During two hours idling, particle samples were collected to provide sufficient mass for the subsequent analysis. The cycle measurements, too, were extended to 3 NEDC cycles for the cars, during a total period of 59 minutes.

The motorbike Euro3-C2-cycle was run for 4,710 seconds. The scooter Euro3-C1 cycle was run for 3,510 seconds.

\section{MEASUREMENT SETUP}

The measurements were all done on a chassis dynamometer located at the official exhaust-gas test center AFHB in Biel (Canton Bern) Switzerland. The test stand is fully instrumented to measure all relevant exhaust-gas parameters including the granulometry. A full-flow CVS-Tunnel is used to collect the particle samples and to measure the gaseous components. The fine particle analysis is done at the vehicle tailpipe, i.e. sampling undiluted exhaust-gas using the minidiluter MD19 provided by Matter Aerosol GmbH. 
Table 3. Essential attributes of the lubrication oils and their metallic additives.

\begin{tabular}{|c|c|c|c|c|c|c|}
\hline & \multicolumn{2}{|c|}{ Renault / Honda } & \multicolumn{2}{|c|}{ Qashqai } & \multicolumn{2}{|c|}{ Riaggio } \\
\hline Lubrication Oil & used & fresh & used & fresh & used & fresh \\
\hline $\begin{array}{l}\text { Oil - Type } \\
\text { Ash content }[\%\}\end{array}$ & \multicolumn{2}{|c|}{$\begin{array}{c}\text { SAE } 15 \mathrm{~W}-10 \\
1.8\end{array}$} & \multicolumn{2}{|c|}{$\begin{array}{c}\text { SAE } 5 \mathrm{~W}-40 \\
1.6\end{array}$} & \multicolumn{2}{|c|}{$\begin{array}{c}\text { SAE } 5 \mathrm{~W}-40 \\
1.6\end{array}$} \\
\hline \multicolumn{7}{|l|}{$[\mathrm{mg} / \mathrm{kg}]$} \\
\hline Sulfur & $6439 / 3170$ & 3011 & 2490 & 2725 & 5000 & 4800 \\
\hline Calcium & $2100 / 1600$ & 1700 & 1438 & 1584 & 2200 & 2200 \\
\hline Phosphorous & $886 / 797$ & 869 & 753 & 895 & 1200 & 1100 \\
\hline Zinc & $1016 / 934$ & 967 & 893 & 984 & 1300 & 1200 \\
\hline Iron & $6.2 / 7.9$ & 1.5 & 32 & 0.9 & 14 & 0.9 \\
\hline Nickel & DL & DL & 0.03 & 0.02 & DL & 0.11 \\
\hline Copper & $0.77 / 3.78$ & 0.01 & 0.04 & 0.03 & 33 & 0.0001 \\
\hline $\begin{array}{l}\text { Operating time } \\
\text { since oil change }\end{array}$ & \multicolumn{2}{|c|}{$1000 / 4000 \mathrm{~km}$} & \multicolumn{2}{|c|}{$25000 \mathrm{~km}$} & \multicolumn{2}{|c|}{$1000 \mathrm{~km}$} \\
\hline
\end{tabular}

Table 4. Test cycles

\begin{tabular}{|c|c|c|c|}
\hline Renault R18 & Honda 450 CBR & Nissan Qashqai & Scooter Piaggio \\
\hline Idling & $\begin{array}{l}\text { Idling } \\
\text { - } \quad 120 \mathrm{~min} . \\
\end{array}$ & Idling $120 \mathrm{~min}$. & Idling $120 \mathrm{~min}$. \\
\hline $50 \mathrm{~km} / \mathrm{h}$. $\quad 20 \mathrm{~min}$. & $\begin{array}{l}50 \mathrm{~km} / \mathrm{h} \\
. \quad 20 \mathrm{~min} .\end{array}$ & $\begin{array}{ll}50 \mathrm{~km} / \mathrm{h} \\
-\quad 20 \mathrm{~min} .\end{array}$ & $\begin{array}{l}50 \mathrm{~km} / \mathrm{h} \\
-\quad 20 \mathrm{~min} .\end{array}$ \\
\hline $\begin{array}{ll}\text { NEDC } & \\
\text { - } & 1187 \mathrm{sec} . \\
\text { - } & 11.028 \mathrm{~km} \\
\text { - } & 33.6 \mathrm{~km} / \mathrm{h}\end{array}$ & 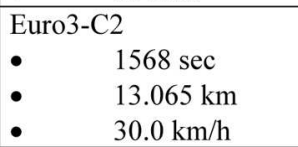 & $\begin{array}{ll}\text { NEDC } & \\
\bullet & 1187 \mathrm{sec} \\
- & 11.028 \mathrm{~km} \\
\bullet & 33.6 \mathrm{~km} / \mathrm{h}\end{array}$ & $\begin{array}{ll}\text { Euro } & 3-\mathrm{C} 1 \\
\bullet & 1170 \mathrm{sec} \\
\bullet & 6.110 \mathrm{~km} \\
\bullet & 18.8 \mathrm{~km} / \mathrm{h}\end{array}$ \\
\hline
\end{tabular}

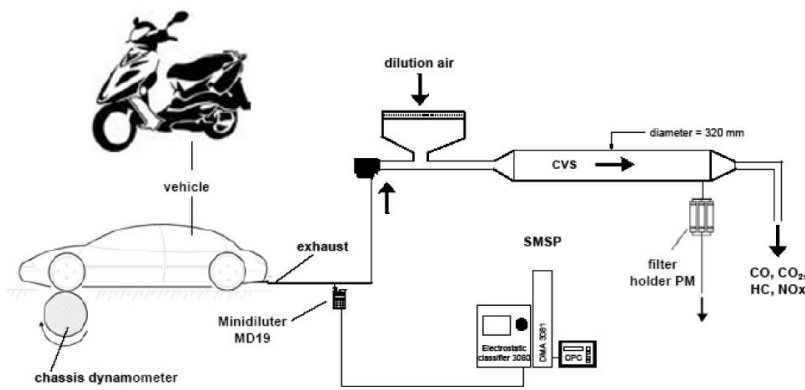

Figure 1. Test schematic for SI cars and SI 2-wheelers at the chassis dynamometer with sampling arrangements and instrumentationfor fine particle analysis.

Gas sampling procedure was according to the PMP Protocol $[\underline{11}, \underline{12}, \underline{13}]$. The gas sample is diluted in the ratio of approx. 1:100. It is then heated to $300^{\circ} \mathrm{C}$ and thus all condensates of volatile substances converted to the gaseous state. Hence, only solid particles are measured. The size distribution is measured using the routine combination of SMPS and CPC. The procedure quantifies the size distribution in the size range $10-400 \mathrm{~nm}$ in 60 size classes. For comparison, the nanoparticles are analyzed with the NanoMet instrument [11]. Its DC and PAS sensors measure the total surface of the aerosols (Fuchs surface) and the content of elemental carbon. The NanoMet data were only used for verification and not further discussed here.
The background particle count is obtained from a fine particle analysis of the ambient laboratory air and in the CVS tunnel without engine exhaust-gas. The measurements are repeated with the inlet tube open and closed. Fig. 2 shows the results.

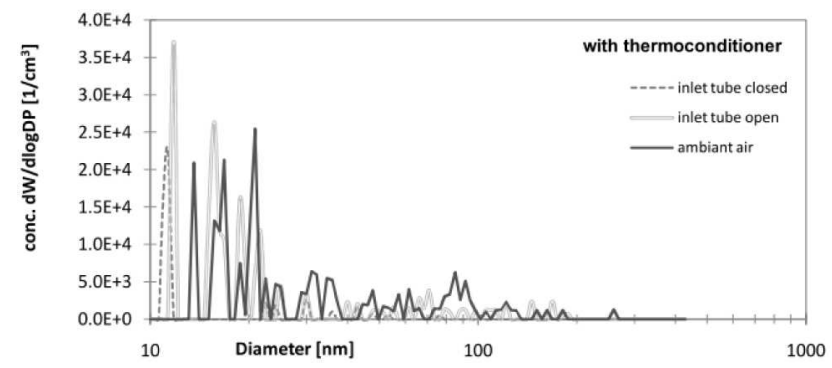

Figure 2. Background values for the lab air and the CVS tunnel without engine exhaust-gas

This gas sample, too, is prepared according to the PMP Protocol, i.e. diluted and heated to $300^{\circ} \mathrm{C}$, thus removing all volatile substances prior to particle counting.

The result is very satisfactory. The total concentration count of particles smaller than $400 \mathrm{~nm}$ is in the range of $1 \times 103$ till $3 \times 103$. This background count is small enough to not affect the emission tests. 
Table 5. Particle mass emissions and composition of the PM sampled from SI-engines

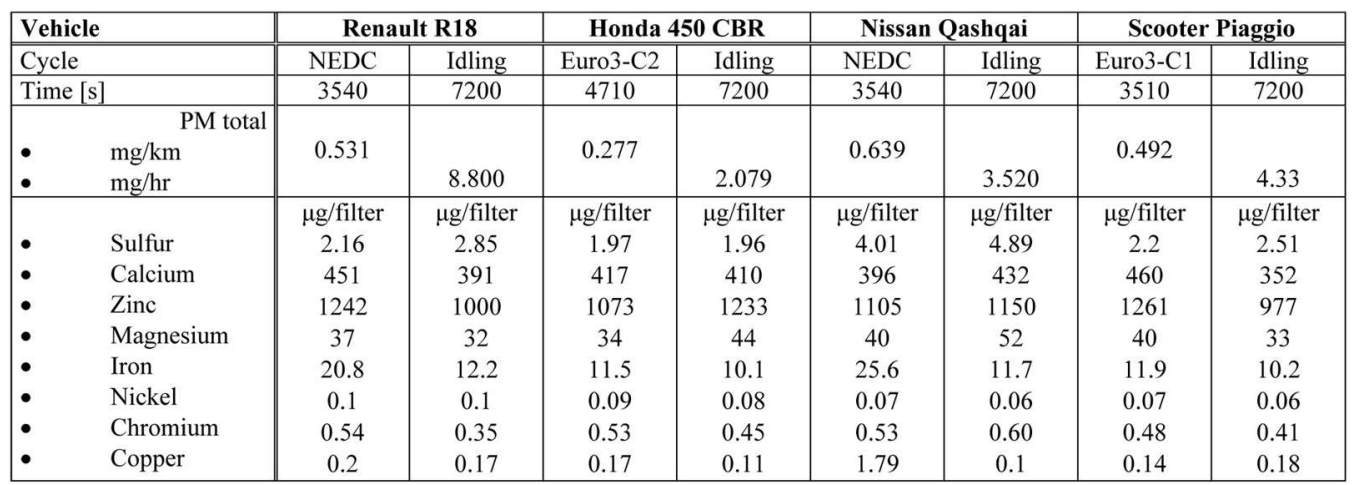

\section{METAL ANALYSIS}

The ultra-trace determination of metals requires a strict optimization of the entire sampling procedure, sample preparation and analysis. Sampling mistakes can yield misleading results.

All samples were digested with acid mixtures in a microwave oven. The vessels used for the digestion should be carefully pre-cleaned and validated before use to achieve best detection limits.

All cleaning digestions must be verified using highly sensitive analytical techniques like ICP-MS (inductively coupled plasma mass spectrometry) to ensure that the vessel background levels are low enough for such ultra-trace analysis. Only ultra-clean vessels should be used.

Depending on the filter material and the pertinent target elements, sampling filters were digested with the following acid mixtures in a microwave oven:

- Nitric acid $\mathrm{HNO}_{3}$

- A mixture of nitric acid $\mathrm{HNO}_{3}$ and hydrogen peroxide $\mathrm{H}_{2} \mathrm{O}_{2}$

- A mixture of nitric acid, hydrochloric acid $\mathrm{HCl}$ and hydrogen peroxide $\mathrm{H}_{2} \mathrm{O}_{2}$

Further details on the digestion procedure, e.g. the exact temperature-time programs for the microwave oven, can be found in [15]. The resulting solutions were analyzed using plasma mass spectrometry ICP-MS. Depending on the analyte elements, either a quadruple ICP-MS (ELAN 6000, Perkin Elmer/Sciex) or a high resolution ICP-MS (ELEMENT 2, Thermo Finnigan) were used.

Contamination risk and memory effects are not negligible especially for ubiquitous metals like Fe. Usually the metal determination is more limited by the sampling procedure and sampling preparation than by detection limits of the analytical method.

\section{RESULTS}

The investigation focused on the particle emissions. Gaseous emissions are not reported.Particle mass emissions and their composition

The particle mass was extracted, from the CVS tunnel using a two-stage filter. This was a Pallflex filter of $47 \mathrm{~mm}$ diameter. Only for the background measurements, a $70 \mathrm{~mm}$ diameter filter was used.

\section{PARTICLE COUNT CONCENTRATION AND SIZE DISTRIBUTION}

Fig. 3 shows the size distribution from the SMPS measurement in the usual definition $\mathrm{dW} / \mathrm{d} \operatorname{logDP}\left[\mathrm{cm}^{3}\right]$ for both the steady-state points $50 \mathrm{~km} / \mathrm{h}$ and idling. Table 5 contains the evaluation of these measurements.

Fig. 3.1.: Car Renault R18. This car has, both at the medium load point and at idling, very high particle emissions. These equal or exceed Diesel engine emissions [2] . There is a bimodal distribution at part load (left Fig.). A soot peak (agglomerated particles) at $100 \mathrm{~nm}$ is exceeded, for smaller particles, by an order of magnitude. Figure 4 illustrates how this bimodal distribution is a superposing of two mutually independent distributions. These could be two particle cohorts, namely the soot particles and the ash particles. Both the logarithmic-normal distributions are also known from the large number of investigations for the particle emissions of combustion engines [16]. From the fitting of both distributions, the characteristic size for both cohorts can be derived, i.e. the pertinent count and the mean particle diameter. These parameters are summarized in Table 5. Here the Renault R18 data, at $50 \mathrm{~km} / \mathrm{h}$, shows a very clear situation. The mean soot particle diameter is $70 \mathrm{~nm}$ and the mean ash particle diameter is $10 \mathrm{~nm}$. At the idling point, this vehicle emits substantially more ash particles. These are obviously agglomerated and have a mean size of $24 \mathrm{~nm}$. The peak soot amplitude is distinctly lower and the particle size slightly higher than at $50 \mathrm{~km} / \mathrm{h}$. 


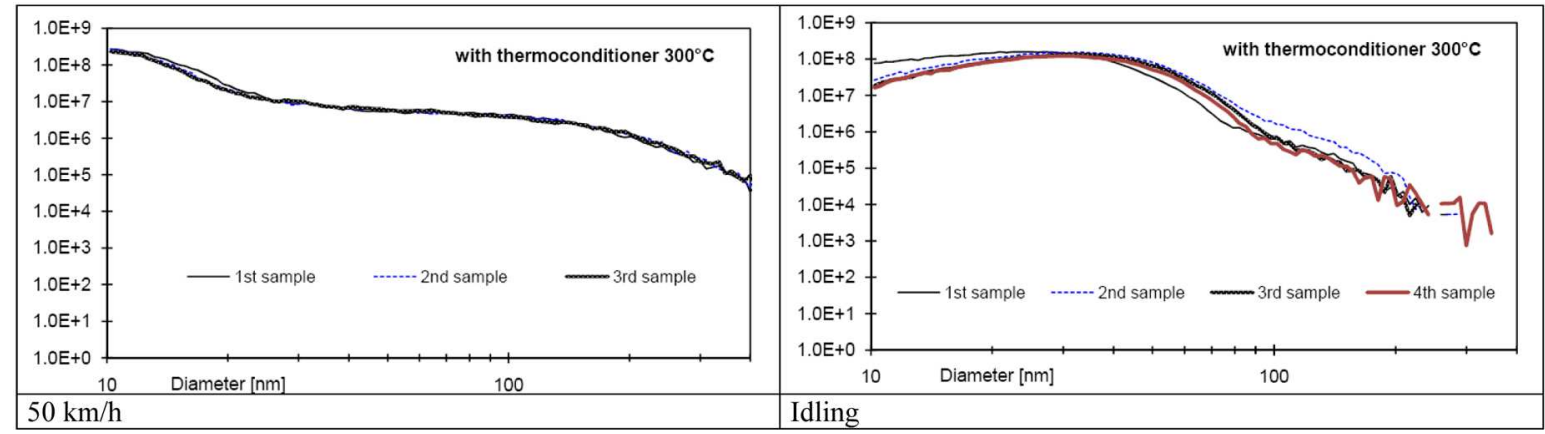

Figure 3.1. Car Renault R18

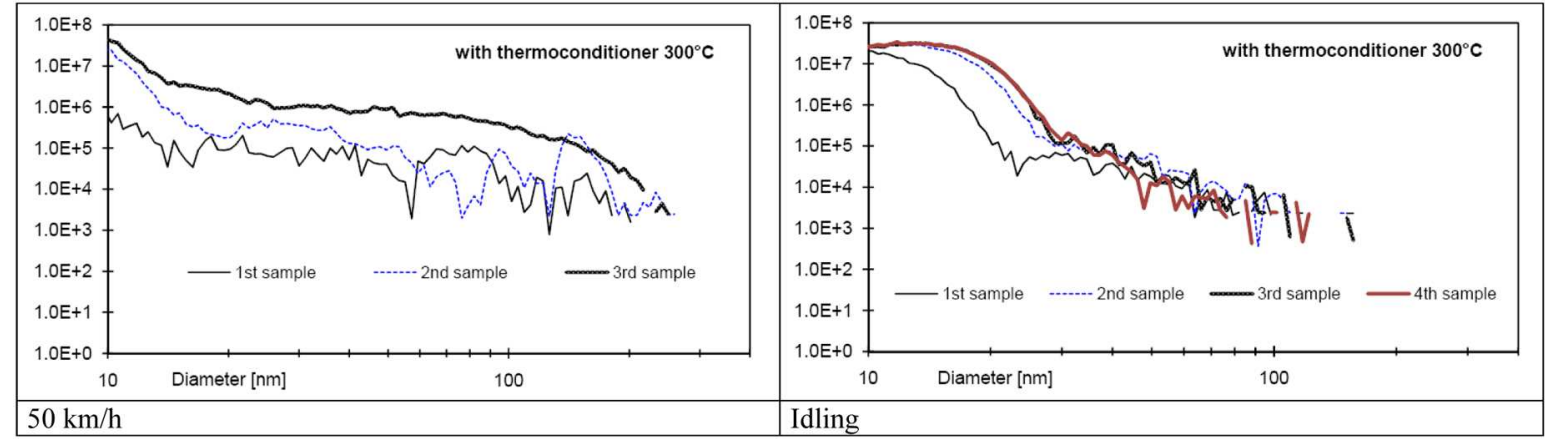

Figure 3.2. Motorbike Honda 450

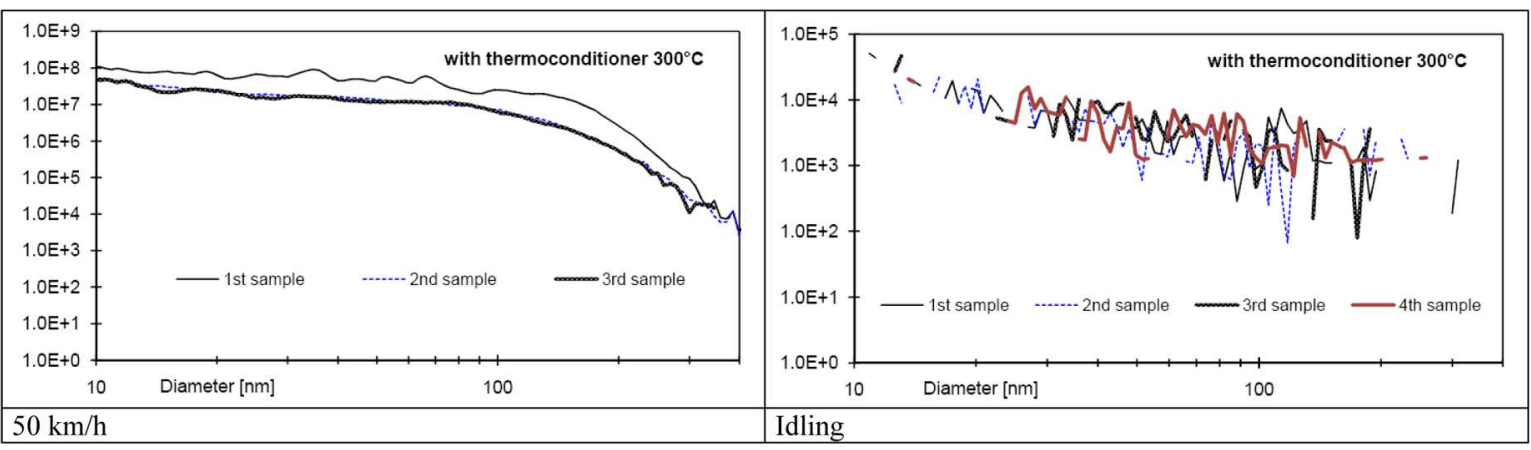

Figure 3.3. Scooter Piaggio

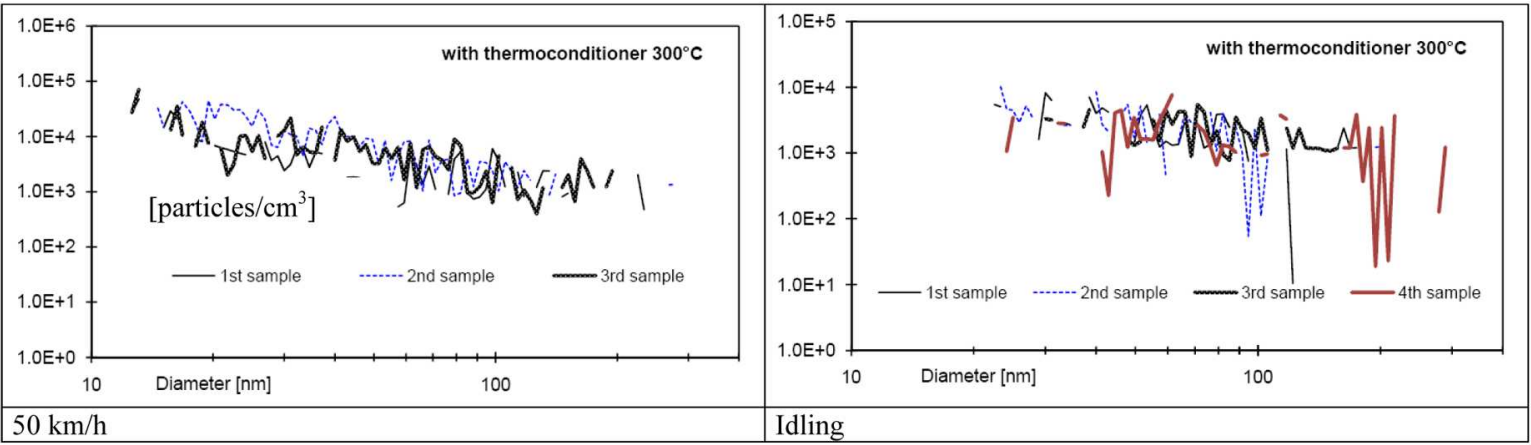

Figure 3.4. Car Nissan Qashqai

Figure 3. Particle concentration in function of particle size of SI engines at $50 \mathrm{~km} / \mathrm{h}$ (left) and idling (right)

Fig. 3.2.: Motorbike Honda 450 CWR: The modality of the size distribution is very clearly evident. Despite the motorbike being relatively lightly used (only about 10,000 $\mathrm{km}$ driven in 22 years), the engine has very high emissions in the ash peak, and at $50 \mathrm{~km} / \mathrm{h}$ also in the soot peak. The particle emissions at idling are only slightly less than the emissions of a Diesel engine [2] . 
Table 6. Characterization of soot peak and ash peak assuming log-normal distributions

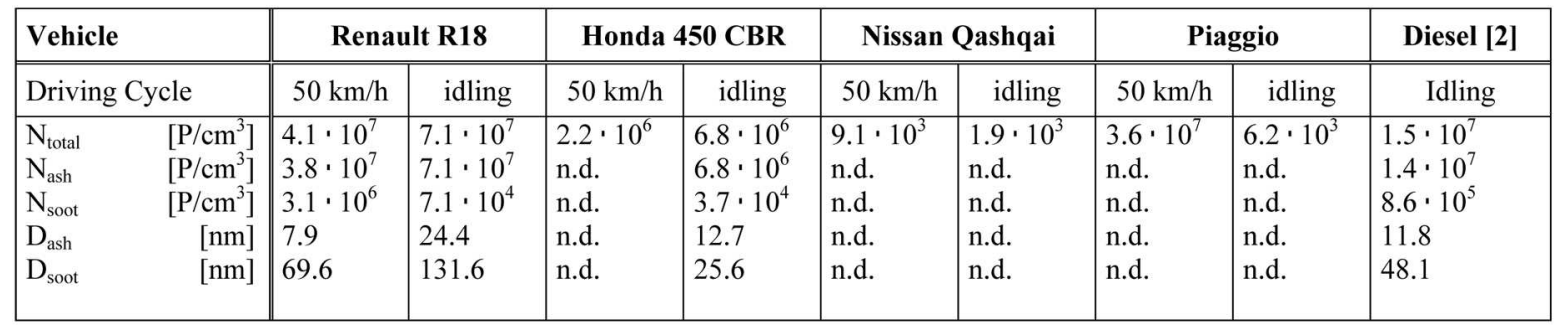

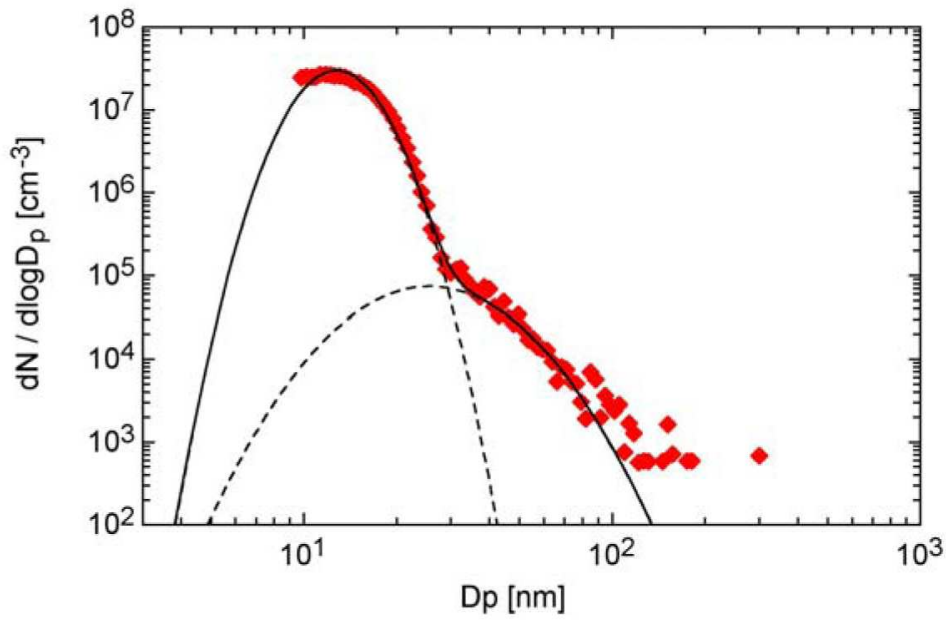

Figure 4. Double LNDF fit, a bimodal particle
distribution [16]. The data pertain to the Honda
motorbike engine at idling.

Fig. 3.3.: Scooter Piaggio: This 1-cylinder/4-stroke scooter engine, with port injection, has very high soot particle emissions at $50 \mathrm{~km} / \mathrm{h}$. These emissions are higher than from the Honda, almost equal to the Renault's emissions, and similar to those from the Diesel. The bimodal distribution is less evident. The particle level remains high down to $10 \mathrm{~nm}$, which is very distressing and must be associated with the lube oil consumption at this operating condition. However, it is difficult to explain why this highly emitting engine emits only very few particles at idling.

Fig. 3.4.: Car Nissan Qashqai: This new car has extremely low particle emissions that hardly exceed the background, neither at $50 \mathrm{~km} / \mathrm{h}$ nor at idling. A bimodal evaluation was impossible. This means that at both investigated operating conditions the lube oil consumption is negligible.

\section{CONCLUSIONS}

Beside soot particles, diesel engines also emit metal oxide particles, generated by wear processes as well as by nucleation during the intense combustion process. Wear processes generate particles in the $\mu \mathrm{m}$ range whereas nucleated particles can be much smaller and normally found in ultrafine nanometer range. These can be: typical abraded metals like $\mathrm{Fe}, \mathrm{Ni}, \mathrm{Cu}$; or metals originating from lubrication oil packages like $\mathrm{Zn}$ and $\mathrm{Ca}$; or metals from fuel additives. All of these become airborne and enter into human breathing environments. Nanosize metal oxide particles are observed to be emitted attached to soot particles and also as free particles in the size range of 10-30 nm with concentrations as high as 108 particles per $\mathrm{cc}$, as observed during idle conditions.

The four SI vehicles in this investigation were selected to compare emissions from heavily abraded engines with those from newer engines. Their past history is known and the vehicles are in a good technical condition. Some were repeatedly tested in time-series investigation and their exhaust gas verified. These four vehicles are certainly not representative of all the SI engines on the roads, but are of course in the cohort. All four vehicles have typical fuel consumption. The four vehicles - including the two older vehicles - consumed very little lubrication oil and do not need topping up between lube oil changes. The investigations indicate that the nanoparticle emissions from SI engines can differ considerably, both for newer engines and also for older engines, but are comparable to typical Diesel engine emissions. The main focuses of this investigation were the metal oxide particles. Very clearly, metal oxides are being emitted in the size range $10-30 \mathrm{~nm}$. This is precisely the size range of maximum alveolar deposition and aggressive tissue penetration. The ash particle concentration mostly exceeds the soot particle concentration and can even exceed ash emissions from Diesel engines.

The data of this work confirm the suspicion that SI engines, too, emit very high concentration of solid particles in the critical size range smaller than $200 \mathrm{~nm}$. Also confirmed is that the emission of ash particles can reach a non-negligible level. The investigations will therefore be continued to more extensively substantiate these conclusions.

Particle emissions generated by internal combustion engines are today recognized as the most serious urban air pollutant. Technical countermeasures are required to eliminate these particles, which are more dangerous the smaller they are. The true toxic substances can be: the elemental carbon of soot; or the organic deposits on the soot particles; or the attached metal oxide particles; or the combination. The definitive cause is still unclear and requires further investigations. Some evidence points to engine emitted metal-oxide particles being those of the most health concern. 


\section{ACKNOWLEDGEMENT}

The authors express the thanks to Mr.Adrian Wichser from the EMPA Federal Laboratories, Inorganic Chemistry for his help and expertise in the size-selective substance analysis of particulate matter.

\section{CONTACT INFORMATION}

Dipl.Ing. Dr.med h.c. Andreas C.R.Mayer, TTM

Fohrhölzlistrasse 14b

CH-5443 Niederrohrdorf

Switzerland

Tel. $+41(56) 4966414$

Fax $+41(56) 4966415$

ttm.a.mayer@bluewin.ch

\section{REFERENCES}

1. Israël, G.W. et al., Analyse der Herkunft und

Zusammensetzung der Schwebestaubimmission, VDI

Fortschritt-Berichte, Umwelttechnik Nr. 92 Analysis of origin and composition of suspended dust

2. Mayer, A., Ulrich, A., Czerwinski, J., and Mooney, J., "Metal-Oxide Particles in Combustion Engine Exhaust," SAE Technical Paper 2010-01-0792, 2010, doi:

10.4271/2010-01-0792.

3. Kittelson, D., Ultrafine Particles from Engines; Vienna University of Technology; 16.Jan.2008

4. Kittelson, D.et al., Real time measurements of ash particle emissions, $14^{\text {th }}$ ETH Zurich Conference on Combustion Generated Nanoparticles 2010

5. Gehr, P. Heyder, J., Particle-Lung Interactions, Marcel Dekker, New York - Basel, 2000, ISBN: 0-8247-9891-0

6. Cascio Wayne, E., Environmental Health Effects of Combustion-Related Ultrafine Particulate Matter, $14^{\text {th }}$ ETH Zurich Conference on Combustion Generated Nanoparticles 2010

7. Karlsson, H. et al.: Size-dependent toxicity of metal oxide particles-A comparison between nano- and micrometer size, Toxicology Letters, 188 (2), 2009, 112-118

8. Diesel Exhaust Aftertreatment, SAE World Congress, Detroit, MI, yearly since 1982 .

9. ETH Zurich Conference on Combustion Generated Nanoparticles, yearly since 1997, www.nanoparticles.ethz.ch

10. Nikolaus, Steininger, European Commission, Automotive Particle Emissions: an update of regulatory Euro 6/VI and UNECE developments, $14^{\text {th }}$ ETH Zurich Conf. on Combustion Generated Nanoparticles 2010

11. Kasper, M., "The Number Concentration of Non-Volatile Particles - Design Study for an Instrument According to the
PMP Recommendations," SAE Technical Paper 2004-01-0960, 2004, doi:10.4271/2004-01-0960.

12. UN-ECE R83 Annex 4 Appendix 5

13. Euro $5 / 6$ for emissions of light passenger and commercial vehicles: EC-Regulation No. 715/2007,

14. http://ec.europa.eu/enterprise/automotive/index_en.htm

15. Mayer, A., Heeb, N., Czerwinski, J., and Wyser, M., "Secondary Emissions from Catalytic Active Particle Filter Systems," SAE Technical Paper 2003-01-0291, 2003, doi: 10.4271/2003-01-0291.

16. Ulrich, A., Wichser, A., Analysis of additive metals in fuel and emission aerosols of diesel vehicles with and without particle traps, Analytical and Bioanalytical Chemistry (2003) $377: 71-81$

17. Maricq, M, How are emissions of nuclei mode particles affected by emission control; HEI-Conf. May 2009

\section{ACRONYMS AND ABBREVIATIONS}

\section{AFHB}

Laboratories for IC-Engines \& Exhaust Emission Control, Biel, Switzerland

CPC

Condensation Particle Counter

CVS

Constant Volume Sampling

DC

Diffusion Charger

DPF

Diesel Particle Filter

ELPI

Electric Low Pressure Impactor

EMPA

Federal Laboratories for Testing Materials

Euro3-C1

European driving cycles for 2 -wheelers $<150 \mathrm{cc}$

Euro3-C2

European driving cycle for 2 -wheelers $>150 \mathrm{cc}$

\section{LNDF}

Log-Normal Distribution Function 


\section{NEDC}

\section{New European Driving Cycle}

nm

Nanometer $=10^{-9} \mathrm{~m}$; nanus (lat) and vóvvo $($ greek $)=$ the dwarf

\section{PAS}

Photoelectric Aerosol-Sensor

PMP

Particle Measurement Program

SI

Spark ignition

\section{SMPS}

Scanning Mobility Particle Sizer (Instruments TSI, USA).

The Engineering Meetings Board has approved this paper for publication. It has successfully completed SAE's peer review process under the supervision of the session organizer. This process requires a minimum of three (3) reviews by industry experts.

All rights reserved. No part of this publication may be reproduced, stored in a retrieval system, or transmitted, in any form or by any means, electronic, mechanical, photocopying, recording, or otherwise, without the prior written permission of SAE. ISSN 0148-7191
Positions and opinions advanced in this paper are those of the author(s) and not necessarily those of SAE. The author is solely responsible for the content of the paper.

SAE Customer Service:

Tel: 877-606-7323 (inside USA and Canada)

Tel: 724-776-4970 (outside USA)

Fax: 724-776-0790

Email: CustomerService@sae.org

SAE Web Address: http://www.sae.org

Printed in USA 